\title{
Corrosion Studies on Powder Metallurgy and Stir Cast Processed Al7075/SiC Nanocomposites
}

\author{
Adil Ahmed.S, P. L. Srinivasa Murthy, D.P.Girish
}

\begin{abstract}
In present study corrosion studies were conducted on Al7075/SiC nanocomposites processed by powder metallurgy and stir casting techniques. The weight percentage of SiC nanoparticles was varied from $1 \%$ to $4 \%$ for preparing the nanocomposites. The corrosion studies were conducted by means of salt spray technique by following ASTM B117 standard in which samples were immersed in highly corrosive environment of 3.5\% NaCl. The weight losses of Al7075 alloy and its nanocomposites showed that with the increase in test duration from 12 to 96 hours, the weight losses of all nanocomposites increased significantly. Powder metallurgy processed nanocomposites showed higher weight loss when compared to those processed using cast route. Corroded surface analysis revealed pitting corrosion as main corrosion mechanism for all materials processed using both the processing techniques. Overall for as cast materials the localized corrosion in form of micro-pits were observed while in case of powder metallurgy processed materials the corrosion was spread over entire surface.
\end{abstract}

Keywords: Nanocomposites; Powder metallurgy; Stir casting; Corrosion.

\section{INTRODUCTION}

Aluminium and its alloy are well known for their low density, moderate strength and good corrosion resistance. Taking a cue from this tremendous amount of research work was carried out to explore aluminium as matrix material for developing composite materials. Since last few decades lot of research has been done in development and characterization of aluminium matrix composites. Aluminium matrix composites are well known for their light weight, wear resistance and high strength properties. Among the widely used micron size particulates to reinforce aluminium matrix were $\mathrm{TiB}_{2}, \mathrm{TiC}, \mathrm{Si}_{3} \mathrm{~N}_{4}, \mathrm{SiC}, \mathrm{Al}_{2} \mathrm{O}_{3}$ and $\mathrm{B}_{4} \mathrm{C}$ [1-3]. But since last couple of decades lot of research is going on reinforcing them with nanosize materials such as $\mathrm{Al}_{2} \mathrm{O}_{3}, \mathrm{CNT}$ and graphene $[4,5]$.

Revised Manuscript Received on August 30, 2019.

* Correspondence Author

Adil Ahmed. S*, PhD Research Scholar VTU Belagavi, and Associate Professor, Department of Mechanical Engineering, Islamia Institute of Technology, Bangalore, India.

P. L. Srinivasa Murthy, 2Department of Mechanical Engineering, Ramaiah Institute of Technology, Bangalore, India.

D.P.Girish, Department of Mechanical Engineering, Government Engineering College, Ramanagara, India.

(C) The Authors. Published by Blue Eyes Intelligence Engineering and Sciences Publication (BEIESP). This is an open access article under the CC BY-NC-ND license (http://creativecommons.org/licenses/by-nc-nd/4.0/)
Due to their small size and large surface area, these nanosize materials have very high level of interactions at the interface due to which most of the physical and mechanical properties are enhanced. Behnamfard et al [6] studied the microstructure and tensile property comparison for hot rolled and rheo-extruded A356/SiC nanocomposites. Both hot rolled and rheo-extruded nanocomposites showed good dispersion of $\mathrm{SiC}$ nanoparticles. Compared to rheo- extrusion, hot rolled nanocomposites showed significant enhancement in tensile properties. In another work, Saadallah et al [7] studied the structural and thermal performance of carbon nanotubes reinforced aluminium nanocomposites. The nanocomposites were subjected to dilatometry measurements and thermogravimetric analysis to study thermal properties. The dilatometric study confirmed the formation of alumina and aluminium carbide at the grain interfaces. Thermogravimetric studies showed that weight loss of nanocomposites was stabilized by the carbon nanotubes as compared to unreinforced aluminium.

Out of all aluminium alloys, AA7XXX series is known to have highest strength owing to its alloying elements. With zinc and magnesium as alloying elements, this alloy series on heat treatment gives very high strength while addition of copper improves the corrosion resistance. Many works have been reported on development of Al7XXX based composites using various techniques out of which stir casting and powder metallurgy are most explored ones. Murthy et al [8] developed Al7075 reinforced with $\mathrm{TiO}_{2}$ and flyash based hybrid composite by stir casting and hot forging routes. With increment in reinforcement content the compressive strength of hybrid composite was found to increase. Addition of multiple reinforcements hampered the thermal conductivity of Al7075 alloy due to scattering of electrons and photons by reinforcements. Kannan and Ramanujam [9] studied the mechanical properties of nano alumina reinforced AA7075 nanocomposites. Nanocomposite showed uniform dispersion of nano alumina and but when the content was increased more than $2 \%$ clustering of particles was observed. Compared to AA7075 alloy the hardness of nanocomposite increased by $63.7 \%$ while tensile strength increased by $60.1 \%$. Most of the studies conducted on Al7075 based composites focused on mechanical properties while focus on corrosion characteristics was very less. 


\section{Corrosion Studies on Powder Metallurgy and Stir Cast Processed Al7075/SiC Nanocomposites}

In this regard the present work is focused on development of $\mathrm{Al} 7075 / \mathrm{SiC}$ nanocomposites processed by two different techniques. The comparative analysis was done to study the effectiveness of processing routes on corrosion characteristics.

\section{EXPERIMENTATION}

Materials

Al7075 alloy was chosen as matrix material owing to its superior strength and numerous applications in various engineering sector. Nano silicon carbide particles were selected as Nano reinforcement in the aluminum 7075 matrix. Percentage of Nano silicon carbide particles were varied from 0 to 4 et $\%$ in steps of $2 \mathrm{wt} \%$ under the both the processing techniques. Al7075 alloy was in the form of ingots for stir casting process where as for powder metallurgy technique powder of size 40-60 microns was used. Al7075 alloy plates were procured from PMC corporation, Bangalore, INDIA and powder was supplied by ACE Rasayan, Bangalore, INDIA. Nano Silicon Carbide powder was supplied by M/s Sonal Chemicals and Plastics, Bangalore, INDIA.

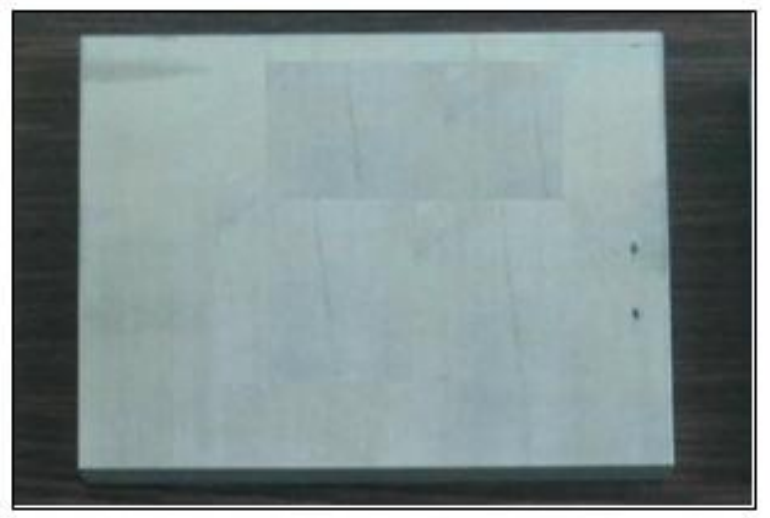

Fig.1 Photograph of Aluminum7075 alloy

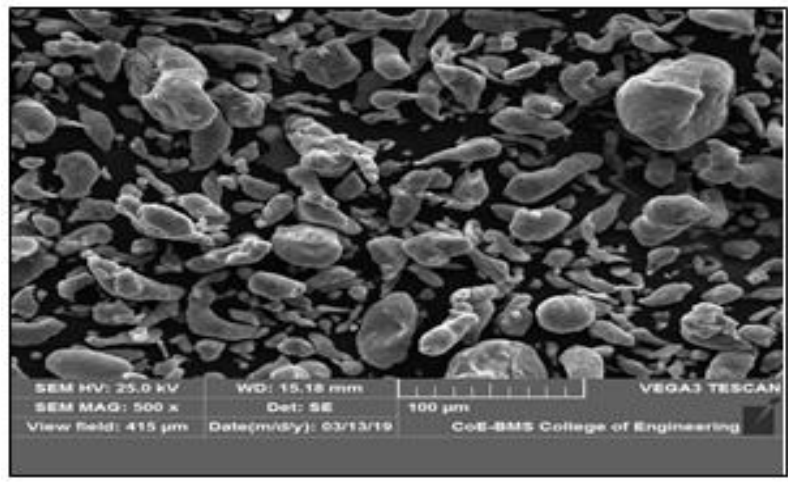

Fig.2 As received Al7075 powder

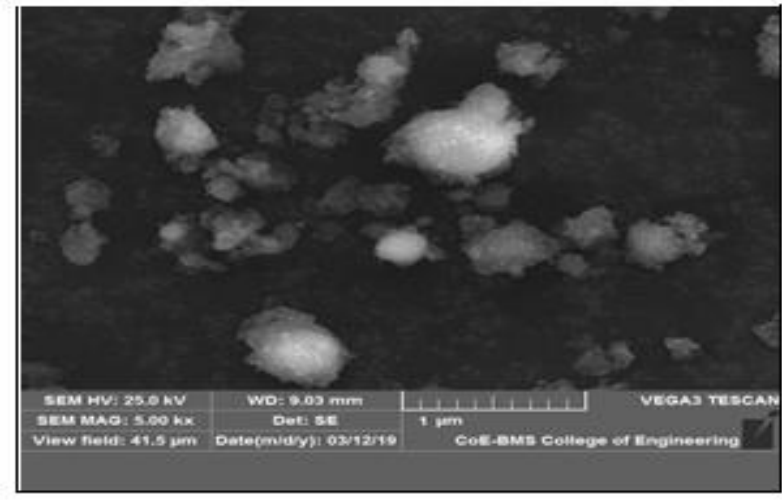

Fig.3a SEM of Nano SiC particles

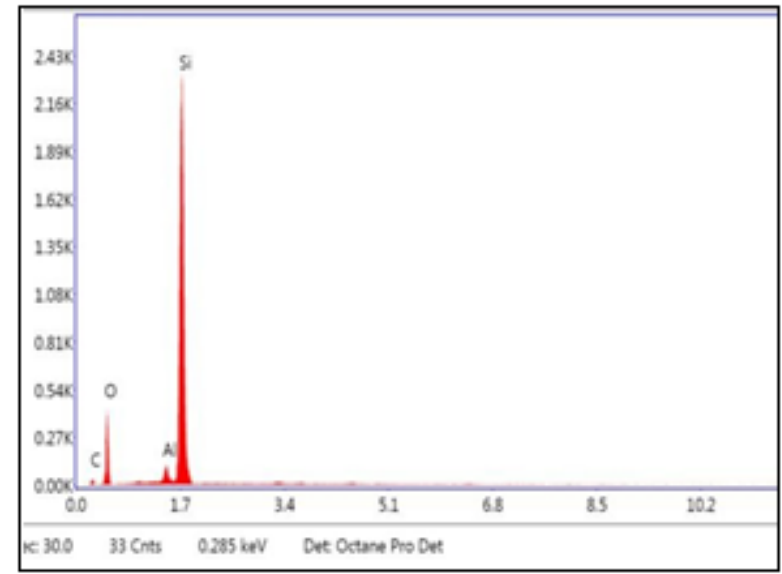

Fig.4b EDS of Nano SiC particles

Preparation of Nano Composite by Stir Casting

The Nano composites was fabricated with the aid of stir casting technique wherein Al7075 turned into melted in graphite crucible at a temperature of $750^{\circ} \mathrm{C}$. Once the melting is accomplished, the degassing of the molten Al7075 is performed the usage of hexachloroethane tablets. After degassing, preheated nano silicon carbide particles were delivered to molten aluminum that is being stirred at 400- rpm. Different weight percent of the reinforcements was introduced to the liquid matrix. The molten Al7075 material with nano silicon carbide powder is stirred for 15 mins ensure dispersion is uniform followed by pouring into cast iron mold

\section{Preparation of Nano composite by Powder Metallurgy}

The planetary ball mill was utilized for blending two or more types of powders uniformly and used to reduce the grain size of metallic powder. a measured quantity of aluminum 7075 powder and nano silicon carbide (1- 4 wt. $\%)$ were mixed in a planetary ball mill to attain a uniformly mixed composite powder. Earlier to mixing, the bowls of the planetary ball mill was wiped with ethanol, dried to remove of moisture. Nano SiC and Al7075 powder added with chrome steel balls with the ball to powder ratio 8:1 was adopted. The Composite powder ball milled for eight hours at three hundred rpm under vacuum inside the planetary ball mill.

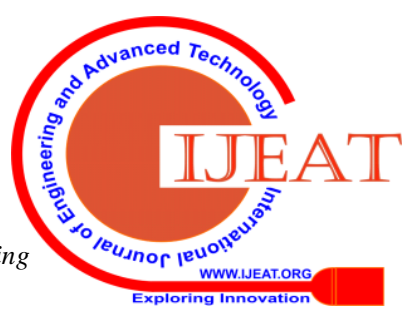


The Al7075 and ball milled composite powder have been filled into die to prepare samples. The composite powder become filled in the die and a load of 400-MPa was applied for five minutes for consolidation using hundred ton hydraulic press. For preparation of samples, the composite powder was compacted into $20 \mathrm{~mm}$ die at a pressure of 400 MPa for period of 5 minutes. before consolidation, the axis of the die and punch was aligned with device spindle axis to apply uniform pressure and to avoid slipping. The compacted composite specimens were sintered using electric powered sintering furnace with alumina tube, heating coil, controller under the provision for argon or nitrogen gas to avoid oxidation. The compacted nanocomposite specimens were sintered in an electric powered furnace at a temperature of $400^{\circ} \mathrm{C}$ for approximately 1 hour in an argon-included environment.

\section{Corrosion Test}

Salt Spray test were done as consistent with ASTM B117 procedure on Al7075 alloy its nano composites in stir casting and powder metallurgy conditions. Machined samples of length of $10 * 10 * 10 \mathrm{~mm}$ cubes were polished for with uniform surface finish. Polished samples were weighed to the third decimal factor. The polished samples have been then subjected to salt spray test, the use of salt spray test chamber. The samples were suspended in salts spray chamber from the vertical and faced an intermittent spray at half hour intervals, containing dissolved 5\% $\mathrm{NaCl}$ (AR Grade) in distilled water for a period of overall of ninety six hours. The $\mathrm{pH}$ and the temperature of the solution had been maintained at 7.08 and $35^{\circ} \mathrm{C}$ respectively. After the test, the samples were cleaned with strolling water and air dried earlier than measuring for weight loss.

\section{RESULTS AND DISCUSSION}

Studying corrosion behavior of materials in high saline environment conditions over extended periods is very important. In standard salt spray test, the material is place in highly corrosive environment of $5 \% \mathrm{NaCl}$ and checked regularly. In present work, the salt spray test was carried out on both alloy and nanocomposites processed under different conditions by following ASTM B117 standard

\section{Effect of reinforcement}

Fig. 4 shows the weight loss of Al7075 alloy and its nanocomposites processed using cast and powder metallurgy technique after subjecting to salt spray test for test duration of 12 hours. To start with it can be observed that the weight loss of Al7075 alloy started to increase with the increase in $\mathrm{SiC}$ nanoparticle content irrespective of processing conditions. In case of cast materials, the lowest weight loss of $0.071 \mathrm{~g}$ was observed for Al7075 alloy while highest weight loss of $0.084 \mathrm{~g}$ was observed for nanocomposite with $4 \% \mathrm{SiC}$ nanoparticles. The increase in weight loss for nanocomposite with $4 \% \mathrm{SiC}$ nanoparticles when compared to Al7075 alloy is $18.30 \%$. In case of powder metallurgy processed materials, the lowest weight loss of $0.074 \mathrm{~g}$ was observed for Al7075 alloy while highest weight loss of $0.086 \mathrm{~g}$ was observed for nanocomposite with $4 \% \mathrm{SiC}$ nanoparticles. The increase in weight loss for nanocomposite with $4 \% \mathrm{SiC}$ nanoparticles when compared to Al7075 alloy is $16.21 \%$. However, one can see that the difference in weight loss of $\operatorname{Al7075}(0.003 \mathrm{~g})$ is comparatively higher than that of difference in weight loss of nanocomposite with $4 \%$ sic nanoparticles (0.002 g). in general the weight loss in case of nanocomposites when compared to that of al7075 irrespective of processing technique is higher which is attributed to pitting corrosion at the matrix/reinforcement interface or at the surface defects such as pores. the addition of sic nanoparticles decreases the polarization resistance which favors the nucleation of pits by the chloride ions $\left(\mathrm{cl}^{-}\right)$present in the nacl solution. with the increase in sic content the number of matrix/reinforcement interfaces also increased which in turn causes more weight loss due to pitting corrosion. this is mainly because addition of sic nanoparticles reduces the kinetic constant $(\mathrm{y}=\mathrm{k} * \mathrm{t}$; $\mathrm{y}-$ weight loss, $\mathrm{k}$ - kinetic constant, $\mathrm{t}$ - time) by reducing the matrix surface area. however the presence of cu along with al forms a galvanic couple and this along with chloride ions leads to formation of pits. due to presence of cathodic reaction the corrosion process takes place and especially in case of nanocomposites the corrosion rate is high when compared to al7075 alloy. however the higher weight loss for powder metallurgy processed material is higher than cast counterparts which is due to presence of sic clusters and high porosity content which enhances the corrosion rates $[10$,

$11]$

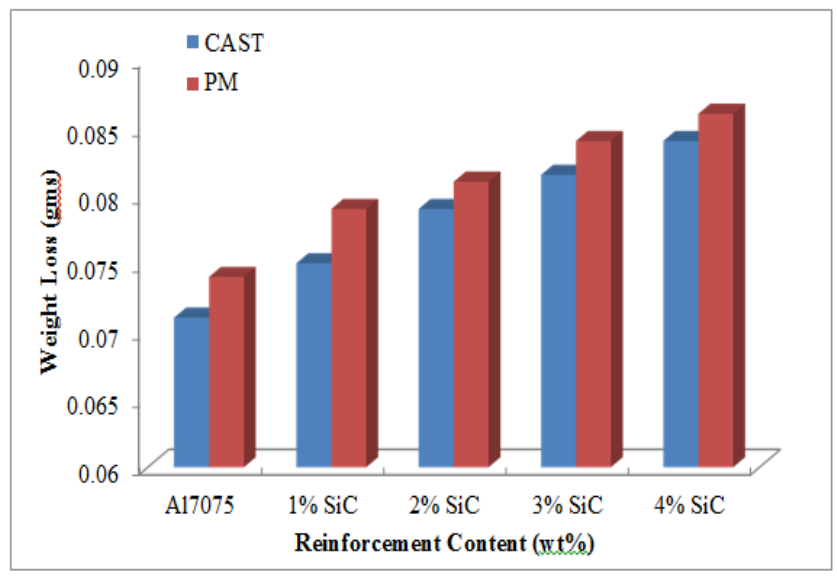

\section{Fig. 5 Weight loss of Al7075 alloy and its nanocomposites as a function of $\mathrm{SiC}$ content}

\section{Effect of Test Duration}

Fig. 5 shows the weight losses of Al7075 alloy and its nanocomposites after subjecting to salt spray test for varying test durations of 12 to 96 hours in the step of 12 hours. To start with it can be observed that the weight loss of Al7075 alloy processed using powder metallurgy and casting technique showed minimum loss while nanocomposite with 4\% SiC nanoparticle processed using casting showed highest weight loss for the test duration of 12 hours. But as the test duration was increased to 24 hours both powder metallurgy processed nanocomposites with $2 \%$ and $4 \%$ showed highest weight loss of 0.088 and $0.089 \mathrm{~g}$ while Al7075 alloy in both the cast and powder metallurgy processing conditions showed minimal weight loss of 0.080 and $0.079 \mathrm{~g}$.
Blue Eyes Intelligence Engineering \& Sciences Publication 


\section{Corrosion Studies on Powder Metallurgy and Stir Cast Processed Al7075/SiC Nanocomposites}

Like this the increase in test duration the weight losses of all nanocomposites especially powder metallurgy processed showed higher weight loss than that of alloy and nanocomposites processed using cast route. By the end of 96 hours test duration the highest weight loss of 0.12 and 0.119 $\mathrm{g}$ was showed by powder metallurgy processed nanocomposites with $2 \%$ and $4 \%$. The minimal weight loss of 0.109 and $0.095 \mathrm{~g}$ was shown by powder metallurgy and cast processed Al7075 alloys. As mentioned earlier the highest weight loss in case of powder metallurgy processed nanocomposites is due to presence of SiC clusters and high porosity content which initiates the corrosion due to decrease the polarization resistance by addition of $\mathrm{SiC}$ nanoparticles. Overall one can observe that the increase in test duration from 12 to 96 hours resulted in increase in weight loss for all materials irrespective of processing conditions.

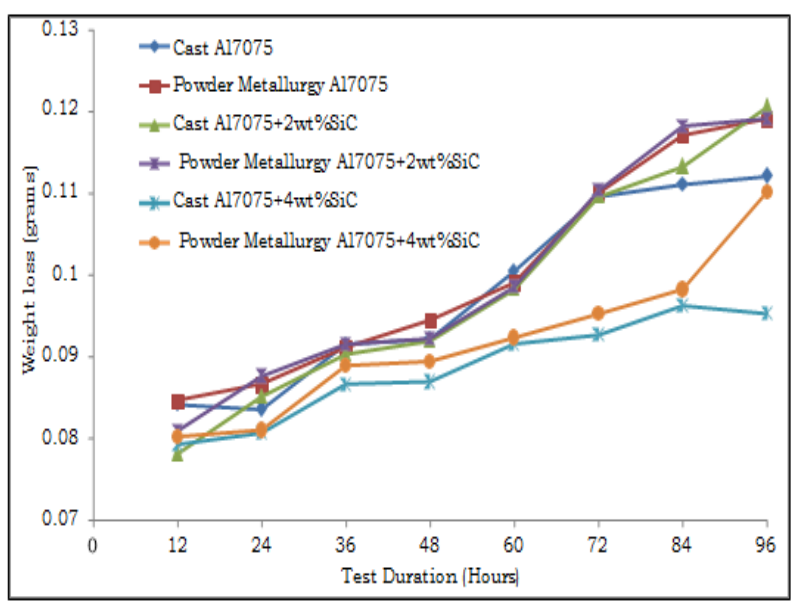

Fig. 6 Weight loss of Al7075 alloy and its nanocomposites with test duration

Corroded surface analysis

Fig. 6 and 7 shows the SEM micrographs of corroded surfaces of Al7075 alloy and its nanocomposites for different test duration (24 \& 96 hours) for powder metallurgy and cast techniques respectively. First let's start with corroded surface analysis of powder metallurgy processed materials for different test durations. Initially formation of $\mathrm{Al}_{2} \mathrm{O}_{3}$ layer was found to be covered all over the surface of Al7075 alloy due to which the one tested at 24 hours test duration showed not much difference in surface as it appears to be quite smooth (see Fig. 6 (a)). However with the increase in test duration to 96 hours the pitting corrosion was seen all over the surface as shown in Fig. 6 (b). This is mainly due to the fact that the transportation of reactive species from $\mathrm{NaCl}$ solution to the Al7075 surface takes place at much longer time due to which the oxide layer might peel off leading to higher weight loss. Similarly this was the case of powder metallurgy processed Al7075 alloy but the pitting was found to be initiated at test duration of 24 hours itself (see Fig. 7 (a)). This can be attributed to the presence of high porosity content in this alloy which facilitated the nucleation of pits by $\mathrm{Cl}^{-}$ions. Further increase in test duration to 96 hours enhanced the adsorption of reactive anion resulting in formation of corrosion pits on the alloy surface leading to higher weight loss (see Fig. 7 (b)).
Fig. 6 (c) and 7 (c) shows the formation of pitting corrosion on the surface of Al7075 nanocomposite with $2 \%$ $\mathrm{SiC}$ nanoparticles tested for 24 hours processed using cast and powder metallurgy technique. The corrosion initiated at the SiC/matrix interface and nucleation of cracks is found around this region. The localized corrosion attack was identified with formation of oxidation products in the interface region. Further with the increase in test duration to 96 hours extensive pitting corrosion on the surface of Al7075 nanocomposite with $2 \%$ SiC nanoparticles was observed and shown in Fig. 6 (d) and 7 (d). The increase in test duration the weight loss or extent or pitting was found to increase which indicates thinning of oxide film by dissolution process. This means that the aggressive anions penetrate the discontinuous protective layer and start reducing its thickness. Fig. 6 (e) and 7 (e) shows the formation of pitting corrosion on the surface of Al7075 nanocomposite with $4 \% \mathrm{SiC}$ nanoparticles tested for 24 hours processed using cast and powder metallurgy technique. It can be seen that with the increase in $\mathrm{SiC}$ nanoparticle content the number of interfaces are also increasing. Due to this the favorable spots for localized corrosion attack are also increasing due to which the pitting is enhanced.

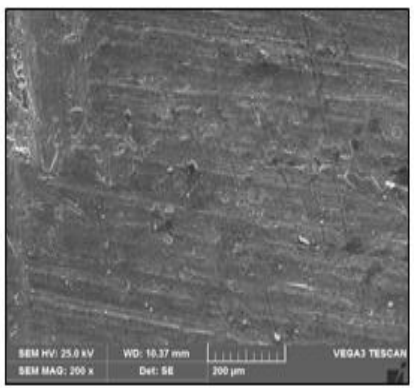

(a) $24 \mathrm{Hr}$

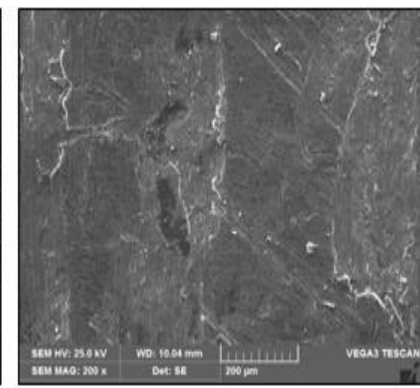

(b) $96 \mathrm{Hrs}$
Al7075 alloy

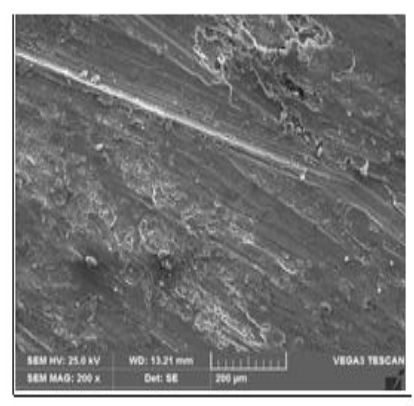

(c) $24 \mathrm{Hrs}$

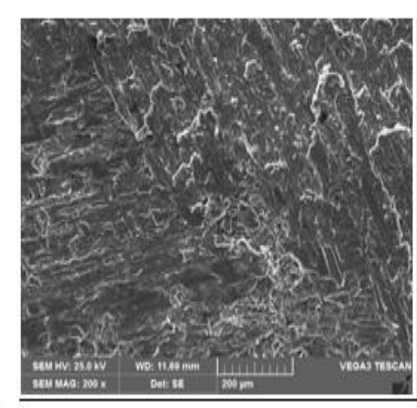

(d) $96 \mathrm{Hrs}$
$\mathrm{Al} 7075+2 \mathrm{wt} \% \mathrm{SiC}$ 


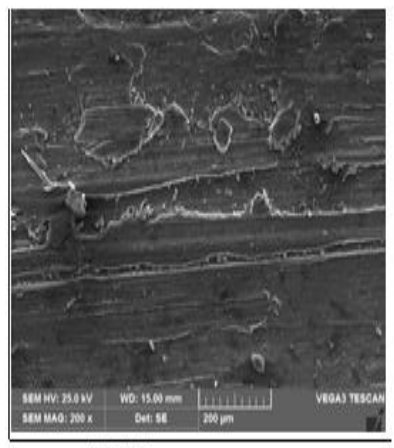

(e) 24 Hrs

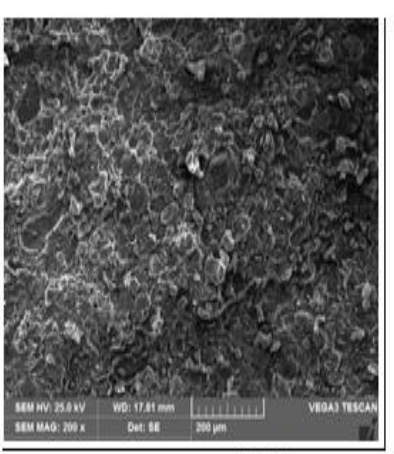

(f) $96 \mathrm{Hrs}$
Al7075+4rit\%:SiC

Fig. 3 Corroded surface of Al7075 and its nanocomposites fabricated by powder metallurgy technique
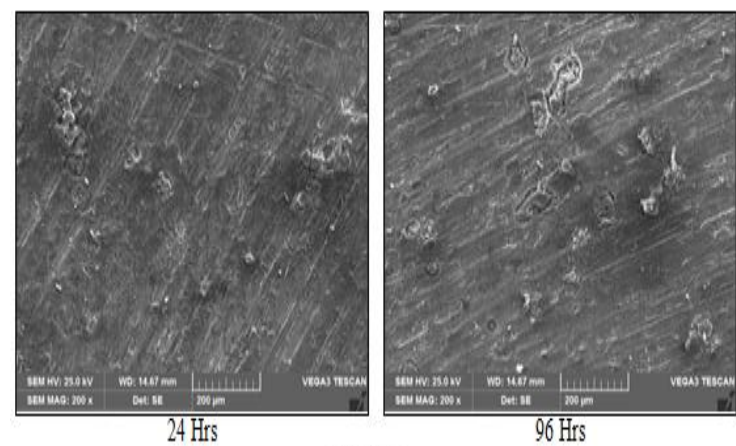

Al7075 alloy

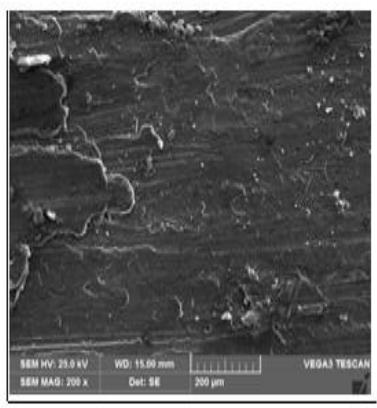

24 Hrs

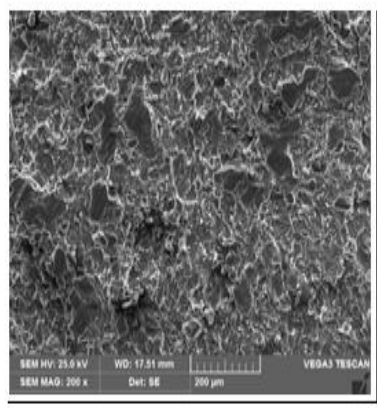

$96 \mathrm{Hrs}$ $\mathrm{A} 17075+2 \mathrm{wt} \% \mathrm{SiC}$

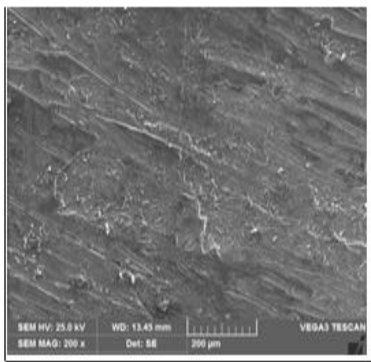

$24 \mathrm{Hrs}$

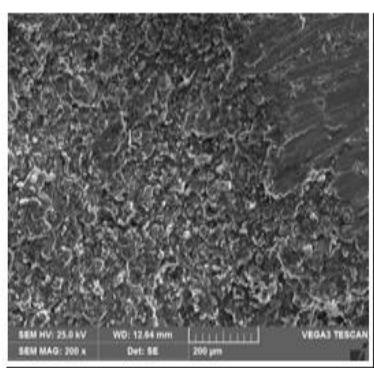

$96 \mathrm{Hrs}$
Al7075+4wt\%SiC

Fig 4 Corroded surface of Al7075 and its nanocomposites fabricated by casting technique

Presence of large number of $\mathrm{SiC}$ nanoparticles ensure that the protective layer is discontinuous due to which the aggressive anions can easily penetrate into the surface. Further with the increase in test duration to 96 hours extensive pitting corrosion on the surface of Al7075 nanocomposite with $4 \% \mathrm{SiC}$ nanoparticles was observed and shown in Fig. 6 (f) and 7 (f). The entire surface of nanocomposites is subjected to pitting rather than few selected regions such as interfaces. The oxidation products resulting from corrosion covered the entire surface of nanocomposites which is attributed to rapid adsorption of anions on to the surface. Overall increase in SiC content increased the number of interfaces leading to rapid adsorption of anions resulting in higher weight losses for these nanocomposites [14-16].

\section{CONCLUSIONS}

Following conclusions were drawn from this present work,

- $\quad$ Salt spray test was conducted in highly corrosive environment of $5 \% \mathrm{NaCl}$ on powder metallurgy and stir cast Al7075/SiC nanocomposites.

- Observations showed that the weight loss in case of nanocomposites when compared to that of Al7075 alloy irrespective of processing technique is higher.

- The weight losses of Al7075 alloy and its nanocomposites showed that with the increase in test duration (12 to 96 hours), the weight losses of all nanocomposites increased significantly.

- $\quad$ Powder metallurgy processed showed higher weight loss than that of alloy and nanocomposites processed using cast route.

- Higher weight loss for nanocomposites was attributed to pitting corrosion at the matrix/reinforcement interface or at the surface defects such as pores.

\section{REFERENCES}

1.C.S. Ramesh, R. Keshavamurthy, S. Pramod, P.G. Koppad, Abrasive wear behavior of Ni-P coated $\mathrm{Si}_{3} \mathrm{~N}_{4}$ reinforced Al6061 composites, Journal of Materials Processing Technology 211 (2011) 1423-1431.

2.R.C. Suryanarayana, S. Khan, P.G. Koppad, Z. Khan, Tribological behaviour of hot extruded Al6061- $\mathrm{Si}_{3} \mathrm{~N}_{4}$ composite, ASME International Mechanical Engineering Congress and Exposition, Proceedings (IMECE) 2 A, 2013.

3.C.S. Ramesh, R. Keshavamurthy, P.G. Koppad, K.T. Kashyap, Role of particle stimulated nucleation in recrystallization of hot extruded $\mathrm{Al}$ 6061/SiC pomposites, Transactions of Nonferrous Metals Society of China (English Edition) 23 (2013) 53-58.

4.K.T. Kashyap, K.B. Puneeth, A. Ram, P.G. Koppad, Ageing kinetics in Carbon nanotube reinforced Aluminium alloy AA6063, Materials Science Forum 710 (2012) 780-785.

5.H.R.A. Ram, P.G. Koppad, K.T. Kashyap, Nanoindentation studies on MWCNT/aluminum alloy 6061 nanocomposites, Materials Science and Engineering A 559 (2013) 920-923.

6.S. Behnamfard, R.T. Mousavian, R.A. Khosroshahi, D. Brabazon, A comparison between hot-rolling process and twin-screw rheoextrusion process for fabrication of aluminum matrix nanocomposite, Materials Science \& Engineering A 760 (2019) 152-157.

7.S. Saadallah, A. Cable, S. Hamamda, K. Chetehouna, M. Sahli, A Boubertakh, S. Revo, N. Gascoin, Structural and thermal characterization of multiwall carbon nanotubes(MWCNTs)/ aluminum (Al) nanocomposites, Composites Part B 151 (2018) 232-236.

8.K.V.S. Murthy, D.P. Girish, R. Keshavamurthy, T. Varol, P.G. Koppad, Mechanical and thermal properties of AA7075/ $/ \mathrm{TiO}_{2} /$ Fly ash hybrid composites obtained by hot forging, Progress in Natural Science: Materials International 27 (2017) 474-481. 
9.C. Kannan, R. Ramanujam, Comparative study on the mechanical and microstructural characterisation of AA 7075 nano and hybrid nanocomposites produced by stir and squeeze casting, Journal of Advanced Research 8 (2017) 309-319.

10. R. Seetharaman, v. Ravisankar, v. Balasubramanian, corrosion performance of friction stir welded aa2024 aluminium alloy under salt fog conditions, trans. Nonferrous met. Soc. China 25(2015) 1427-1438.

11. S. O. Adeosun, O. I. Sekunowo, S. A. Balogun, and V. D. Obiekea, Corrosion behaviour of Heat-Treated AluminumMagnesium Alloy in Chloride and EXCO Environments, International Journal of Corrosion, Volume 2012, Article ID 927380, 2012.

12. M.A. Adnan, K. Kee, P.B. Raja, M.C. Ismail, S. Kakooei, Influence of heat treatment on the Corrosion of Carbon Steel in Environment containing carbon dioxide and acetic acid, IOP Conf. Series: Materials Science and Engineering 370 (2018) 012039.

13. P. Prabhuraj, S. Rajakumar, V. Balasubramanian, Optimising salt fog corrosion parameters to minimising the corrosion rate of AA7075-T651 alloy, Materials Today: Proceedings 5 (2018) 14573-14582.

14. A. Pardo, M.C. Merino, R. Arrabal, S. Merino, F. Viejo, M. Carboneras, Effect of Ce surface treatments on corrosion resistance of A3xx.x/SiCp composites in salt fog, Surface \& Coatings Technology 200 (2006) 2938-2947.

15. R Keshavamurthy, BE Naveena, A Ahmed, N Sekhar "Corrosion characteristics of plasma sprayed flyash-SiC and flyash- $\mathrm{Al}_{2} \mathrm{O}_{3}$ composite coatings on the Al-6061 alloy" Materials Research Express, Vol.6, No.8, June 2019.

16. GSP Kumar, R Keshavamurthy, P Kumari, S Manjoth, JT Kavya "Electrochemical behavior of cast and forged aluminum based in-situ metal matrix composites" AIP Conference Proceedings 2080 (1), 020008, 2019. 